\title{
Physico-chemical properties of palm olein fractions as a function of diglyceride content in the starting material
}

\begin{abstract}
Crude olein preparations with different amounts of diacylglycerols (DAG) were refined, bleached and deodorized (RBD) prior to the dry fractionation process. The RBD olein samples with different amounts of DAG were then individually fractionated into low-melting (super olein) and high-melting fractions (soft stearin). Physical and chemical characteristics, i.e. iodine value, cloud point, slip melting point, triacylglycerol (TAG) and DAG profile, fatty acid composition, thermal profile and solid fat content, of the super olein and soft stearin fractions were analyzed. The TAG profile obtained from the RBD olein having a low DAG content $(0.89 \%)$ showed a higher amount of the diunsaturated TAG, i.e. dioleyl pamitoyl glycerol, in the olein fraction (57.3\%). This, consequently, led to super olein fractions with a better iodine value (IV 65) and the cloud point at $1.3^{\circ} \mathrm{C}$, compared to nontreated super olein (DAG 5\%) with an IV of 60.5 and the cloud point at $4.1^{\circ} \mathrm{C}$. (C) 2005 Wiley-VCH Verlag GmbH \& Co. KGaA.
\end{abstract}

Keyword: Cloud point; Dry fractionation; Eutectic effect; High-melting fraction; Iodine value; Low-melting fraction 